\title{
PREVALENCE OF DEPRESSION IN UNDIAGNOSED POPULACE; A STUDY ON GENDER AND AGE
}

\author{
Syed Zain Azher ${ }^{1}$, Shamoon Noushad ${ }^{1}$, Nida Naeem ${ }^{1}$, Sadaf Ahmed ${ }^{1 \& 2} \&$ Nelofer Sultana ${ }^{3}$ \\ 1. Psychophysiology Research Division, Advance Educational Institute \& Research Centre \\ 2. Department of Physiology - University of Karachi \\ 3. Shaheed Mohtarma Benazir Bhutto Medical College \\ Corresponding author: zain@aeirc-edu.com
}

\begin{abstract}
Depression is a psychological disorder that affects mental state of an individual for a long and short period of time the mental disturbance sometimes occurs due to sadness. Depression is the feeling of past and present experiences in one's life but another feeling often goes together with the depression that is the future feeling. The purpose of this study is to present the vulnerability rate to depression in relation to age and gender in general population of Pakistan .The data was collected from general population in Pakistan from 228 subjects. The integration of age and depression was investigated in different age groups of teenagers (12-19 years), young adults (20-30years) and adults (>30 years).The age and gender difference in relation to depression was studied through a 21-item BDI-II (Beck Depression Inventory-II) Scale \& result analyzed by SPSS 20.0. Results shows females are at higher risk of depression as compared to Male however according to age teenagers are at higher risk.

KEYWORDS: depression, age, gender, BDI-II Scale
\end{abstract}

\section{INTRODUCTION:}

Depression is a serious psychological disorder that affects mental state of an individual for a long time (Sandy, 2014). This mental disturbance sometimes occurs due to sadness. Sadness is a natural feeling that lasts mostly for few minutes but when it goes longer than it is an indicator that person is going through a painful state of mind and body to which we called as depression (Roy, 2005). Depression is the feeling of past and present experiences in one's life but another feeling often goes together with the depression that is the future feeling (although future may be the next minute or hour). We refer that feeling as Anxiety (Butrym, 1983). Depression is not a personality defect but it is actually a disease very painful for those who have it and more difficult for its family and friends. It afflects people of all ages, genders and background. Depression affects a person's mood, behavior, physical changes in the body accompanied by aches and pain. Person may feel angry, irritable or tired (Roy, 2005). Clinically depression is a feeling of sadness, loss, anger or frustration that is the mood disorders and they interfere with daily life for weeks or longer (La Torre, 2011). Every minute of the day our brain is going through complex physiological changes that involve emotions and thoughts as well. This may happen due to the production and breakdown of various chemicals like hormones and neurotransmitters (Miller, 2008). Imbalance of neurotransmitters and hormones inside and outside the brain cells of body and making the brain cells more vulnerable to depression. The relationship between depression and neurotransmitter is very strong and it can be judged by giving any antidepressant to the depressed person. It will clearly be observed that the serotonin levels lowers down while taking the drug and the person will feel better. Besides neurotransmitter, other chemical involve are the Hormones that affects mood. Hormones play a greater role in causing depression, when a person is going through any stressful situation, the cortisol level will rise depending on the intensity of depression that how much depression the person feel. The level of cortisol gradually lowers down when the stress passes but if it remains higher for a long time than it might lead to high blood pressure that eventually causes the person more vulnerable to depression (Miller, 2008). Continuous sad mood, little or no interest in activities that were previously enjoyed significant changes in appetite, trouble falling asleep or oversleeping, loss of energy, worthlessness feelings with irrelevant regret, difficult in thinking and concentration, frequent thoughts of death or suicide are the symptoms of Depression (James, 2014). Men and Women have equal chances of developing depression but the women depression ratio is very high as they feel depression more deeply and show very clear response like becoming sad, tearful and hope less. Lack of social support increases vulnerability rate to depression in all women who are divorced, widowed, and single or married everyone feels depression at equal rates. (Hales, 2010) Although Men depression ratio is very high but they show different responses then women. They become irritated or fatigued and they are more drowned to lose their lives and feel like they are dead from inside. The suicidal rate is also very high in men them women with a ratio of 4:1(Hales, 2010) and there is a complex relationship between depression and age with the rates of depression seen higher in younger adults. The key contributions to depression include any abusive substance like alcohol or cigarette and sleep loss in young individuals. However Epidemiologic and clinical studies reviewed the relationship between depression and disability in older adults opening a new way to the directions for the future research (Bruce, 2001) Family history of depression also plays a great role in developing depression among young persons and it has also been noticed that teens that spend more time in watching television or spending time on computer are at a greater risk of developing depression. (Myrna, 2008). Depression in indicated by cigarette smoking as more teens or people are under the false impression that smoking will make them feel better. This is actually a false perception, nicotine makes the depression symptoms worsens by altering the brain chemistry (Zain, 2012). The purpose of this study is to present the vulnerability rate to depression in relation to age and gender in general population.

\section{METHOD}

The sample of Participants was drawn from randomly selected individuals with $(\mathrm{N}=228)$ that include females $(\mathrm{N}=155)$ and males $(\mathrm{N}=73)$. The sample consists of 31 (12-19 years) age teenagers, 26 (20-30 years) young adults and 171 (>30 years) Adults. Participants completed the Beck Depression Inventory- II ( BDIII), a 21-item measures of depression symptoms severity of which is rated on 4-point likert scale (0-3 point anchors), with items summed to form a total score. The instrument has been designed with a scale that rates the level of depression for the participants. 
The BDI-II measures level of depression with the following scale, $0-14=$ minimal or No depression, $15-20=$ Mild depression, 21-29= Clinical or borderline depression, 30-63= Severe depression. The data was collected by survey method Survey was designed to study the vulnerability rate to depression in different age groups of male and female. The study is a prospective study that is being carried out in different areas of Pakistan through e-mail and on the spot filling of the Questionnaire. Questions were asked that look at the individuals mood and physical state (less interest in doing things, feeling of sadness and hopelessness, trouble concentrating on things, feeling tired or little energy, trouble falling asleep, suicidal thinking) and the questions about the current feeling state and how you feel about the future \& Psychological depression this includes the questions about the alcohol or smoke use, any recent or past significant stressors or if they are taking any antidepressant to release their depression. The questions also includes related to family support, parents attitude with the participant and parents relationship with each other. All these are important aspects to evaluate the psychological history of depression.

RESULT:

According to the analysis of the data recorded by calculating the depression rate among different age groups It was noted that young Adults mostly between the ages (20-30 years) are at greater risk of developing depression when we checked on a large sample size, $8.33 \%$ of the young adults are at the risk of depression. The risk of developing depression among teenagers is very low only $1.3 \%$ teenagers are at higher risk. The adults with an age of greater than 40 shows $0.44 \%$ ratio at the risk of developing depression. According to the study report while considering depression in relation with gender, female shows increased ratio of depression as compare to male. $8.77 \%$ females were at the risk of developing depression $1.32 \%$ were at the risk of developing depression.

\section{DISCUSSION:}

Among many universal facts it is also very well known that number of female depression sufferers are more than male depression sufferers with a ratio of $2: 1$ which means that an average of two women experience major depression to every one male sufferer (Nolen-Hoeksema, 1986). Practically no such difference have been found for depression in terms to gender but then why women are more at a risk of depression? Many surveys have been done to study why women are more vulnerable to depression. Studies suggest that women an experience loses more

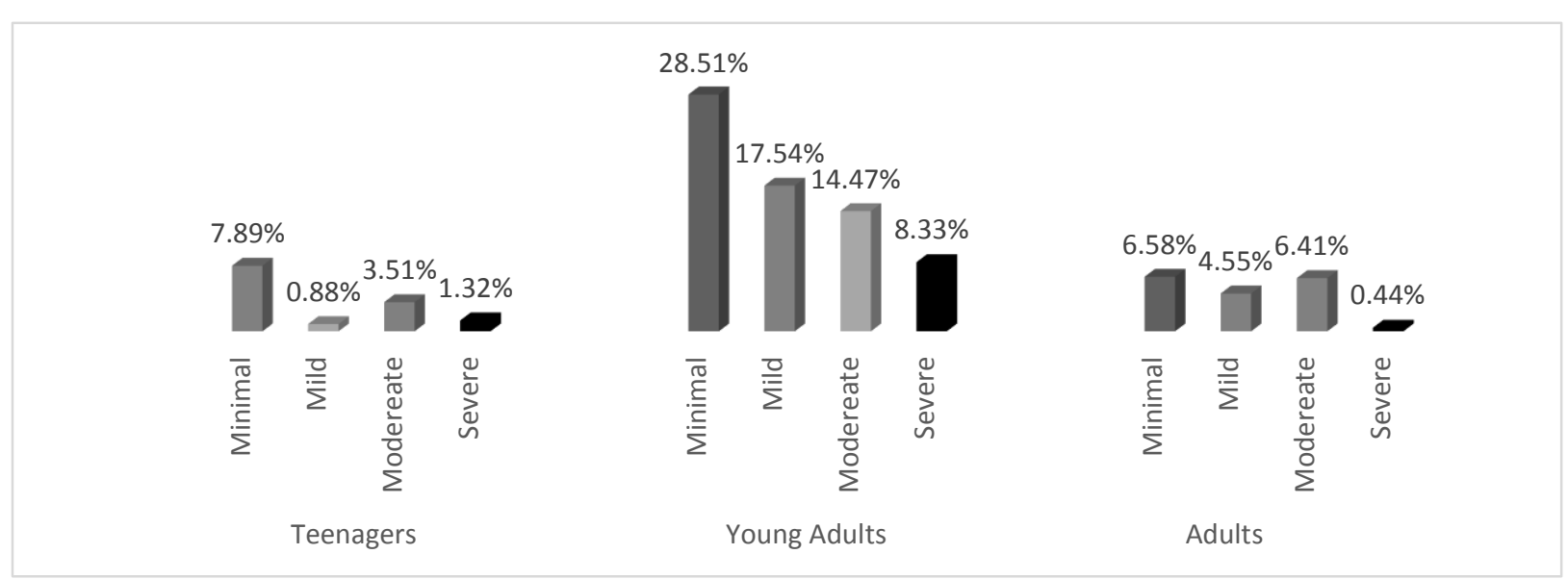

Graph 2 : This graph depression level according to Age

Minimal Mild Modereate Severe $\quad$ Minimal Mild Modereate Severe

Graph 1: This graph depression level according to Gender

Page $\mid 21$ 
deeply that makes them more vulnerable to depression. Marital status is another factor that shows a greater difference of men and women depression. Estimations suggests that married men have lower rate of depression than single men but when it comes to female depression level seems to be the same for women who are married, divorced and those who had never been married. Hormonal shifts also play a very vital role for developing depression in women during pregnancy. These are just the hypothesis and testable ideas that have a chance to be proved as right or wrong (DePaulo, 2002).A longitudinal study suggests that the peak age to study vulnerability to depression is $15-18$ years, it is the most critical time to observe the higher risk of depression at this age and it also shows greater gender difference between the ages 13-15 years showing female sufferers greater than male (Hankin, 2001). A psychopathological approach is required to study depression in children and young adults (Cicchetti, 1998). Prevelance studies tells us that psychologically disturbed children are at more greater risk of developing depression especially those that have a history of Psychiatric disorders are at 3 times of greater risk for developing depression than those who had no psychological symptoms (Costello, 2003). Psychological symptoms include hopeless feelings, with poor concentration, having less energy for doing things and sometimes lead to suicidal thinking and self-criticism (Robinson, 2008). There is a very easy to escape from problems or troubles and most people in our society attempt to do that. When they are sad and want to relieve their sadness they mistakenly belief that drugs are a solution This is the easiest way that most teenagers adopt and it is also seen that if a close family member is an alcoholic, an experimenting teen is at a great risk (Wilkinson, 1994). If a psychiatrist diagnosed depression than the fastest way to feel better is the combination of medication and psychotherapy through talking with a therapist. There are many medicine designed for this purpose that helps to feel better while recovering from illness under the proper guidance of an expert under whose observation the medications effects and its changes to the personality can be seen (Cobain, 2007) Patients show positive attitude in their performance when taking any professional help such as an antidepressants or having discussions with the experts. For the treatment of depressed patients group counseling is very necessary while educating the patients for the primary care of the depressed patients. (Hansson, 201).

\section{CONCLUSION:}

Rate of depression such as mild, moderate and severe was observed higher in the young Adults groups than adults and was found to be lowest in the teenagers. Adults have shown a different response as the age increases they show little interest in physiological activities and there severity to depression decreases. With the passage of time as they move towards older age they show hopelessness feelings towards life and their response towards severity of depression is minimal. Teenagers are independent and free from any kind of responsibilities and fewer teens were at clinical or borderline depression. According to the gender differences females show greater response towards the severity of depression than males. This has also been proven from many past researches that women are more vulnerable to depression than men and they get upsets quickly at minor annoyances. Depression symptoms often go together with anxiety so there might be a possibility of anxiety along with depression. Scientist are still struggling to maintain and develop the reasons behind the women depression rate as women's attempt to obtain a position equal to that of men in society.

\section{REFERENCES:}

- Bruce, M. L. (2001). Depression and disability in late life: directions for future research. The American Journal of Geriatric Psychiatry, 9(2), 102-112.

- Cicchetti, D., \& Toth, S. L. (1998). The development of depression in children and adolescents. American psychologist, 53(2), 221.

- Cobain, B., \& Elizabeth, V. (2007). When Nothing Matters Anymore: A Survival Guide for Depressed Teens. Minneapolis, MN: Free Spirit Pub, Print. pg 123

- Costello, E. J., Mustillo, S., Erkanli, A., Keeler, G., \& Angold, A. (2003). Prevalence and development of psychiatric disorders in childhood and adolescence. Archives of general psychiatry, 60(8), 837-844.

- DePaulo Jr, J. R., \& Horvitz, L. A. (2002). Understanding depression: What we know and what you can do about it. John Wiley \& Sons.

- Hales, D. (2011). An Invitation to Health: Choosing to Change. Cengage Learning.

- Hankin, B. L., \& Abramson, L. Y. (2001). Development of gender differences in depression: An elaborated cognitive vulnerability-transactional stress theory.Psychological bulletin, 127(6), 773.

- Hansson, M., Chotai, J., \& Bodlund, O. (2012). What made me feel better? Patients' own explanations for the improvement of their depression. Nordic Journal of Psychiatry, 66(4), 290-296.

- $\quad$ La Torre, G., \& Saulle, R. (2011). David Crawford, Robert W. Jeffery, Kylie Ball, and Johannes Brug (eds). Obesity Epidemiology. from Aetiology to Public Health. The European Journal of Public Health, 21(5), 676-676.

- $\quad$ La Torre, G., \& Saulle, R. (2011). David Crawford, Robert W. Jeffery, Kylie Ball, and Johannes Brug (eds). Obesity Epidemiology. from Aetiology to Public Health. The European Journal of Public Health, 21(5), 676-676.

- Miller, Allen R. (2008).Living with Depression. New York, NY: Facts On File.

- Nolen-Hoeksema, S., Girgus, J. S., \& Seligman, M. E. (1986). Learned helplessness in children: A longitudinal study of depression, achievement, and explanatory style. Journal of personality and social psychology, 51(2), 435.

- $\quad$ Robinson, P., \& Strosahl, K. (2008). The mindfulness and acceptance workbook for depression: Using acceptance and commitment therapy to move through depression and create a life worth living. New Harbinger Publications.

- Roy, J.R. (2005). Depression New York: Benchmark Books, Print.pg 10, 11

- Sandy Street (2014) Depression in Women:Emphasis on the Impact of Marriage and Motherhood, University of Evansville, retrived from http://faculty.evansville.edu/j13/psych490/BEST\%20SENIO R\%20THESES/06\%20Street.doc

- Zain, A., Sadaf, A., Shamoon, N., Zainab, Q., \& Azam, Y.(2012). The major apprehensions in young chronic cigarette smokers to quit smoking, FUUAST Journal of Biology, 2 (2), 59-63 
- Wilkinson, Beth. (1994).Drugs and Depression. New York: Rosen Pub. Group.
- James Hunter \& NIMH (2014). Research on Depression. Retrieved http://psychcentral.com/disorders/depressionresearch.htm 